\title{
Language, Truth, and Logic and the Anglophone reception of the Vienna Circle ${ }^{1}$
}

\author{
Andreas Vrahimis (University of Cyprus)
}

[Draft, forthcoming in Adam Tuboly (ed.), The Historical and Philosophical Significance of Ayer's Language Truth and Logic, Hampshire: Palgrave Macmillan.]

\begin{abstract}
A. J. Ayer's Language, Truth, and Logic had been responsible for introducing the Vienna Circle's ideas, developed within a Germanophone framework, to an Anglophone readership. Inevitably, this migration from one context to another resulted in the alteration of some of the concepts being transmitted. Such alterations have served to facilitate a number of false impressions of Logical Empiricism from which recent scholarship still tries to recover. In this paper, I will attempt to point to the ways in which LTL has helped to foster the various mistaken stereotypes about Logical Empiricism which were combined into the received view. I will begin by examining Ayer's all too brief presentation of an Anglocentric lineage for his ideas. This lineage, as we shall see, simply omits the major $19^{\text {th }}$ century Germanophone influences on the rise of analytic philosophy. The Germanophone ideas he presents are selectively introduced into an Anglophone context, and directed towards various concerns that arose within that context. I will focus on the differences between Carnap's version of the overcoming of metaphysics, and Ayer's reconfiguration into what he calls the elimination of metaphysics. Having discussed the above, I will very briefly outline the consequences that Ayer's radicalisation of the Vienna Circle's doctrines had on the subsequent Anglophone reception of Logical Empiricism.
\end{abstract}

\section{Introduction}

In the somewhat apologetic introduction to the second edition of Language, Truth, and Logic ( $L T L)$, published a decade after the first edition in 1946, A. J. Ayer (1946, p. 5) calls the book "a young man's book [...] written with more passion than most philosophers allow themselves to show, at any rate in their published work". According to Ayer, this might help account for its having reached "a larger audience than it might have had otherwise" (ibid.). Though Ayer's initial expression of regret regards merely the tone of the book, the introduction of the second edition goes on to develop his well-known series of extensive revisions to the core Logical Empiricist doctrines presented in the first edition. This includes, among other things, a discussion of the verification principle that leads him to a substantially weakened version by comparison to the bold claims of the first edition. ${ }^{2}$

Yet some of what Ayer had tried to excuse as an effect of youthful passion, and what we may with hindsight now see as being simply erroneous, still survives after Ayer's various revisions to the book. $L T L$ undeniably played a crucial role in bringing some of the Vienna Circle's interwar debates to the forefront of Anglophone philosophy (especially during the

\footnotetext{
${ }^{1}$ This paper was first presented in 2018 at the conference on 'The Historical and Philosophical Significance of Ayer's Language, Truth and Logic' at the University of Pécs, organised by the Hungarian Academy of Sciences and the "Empiricism and atomism in twentieth-century Anglo-Saxon philosophy" Research Group. I owe many thanks to all those present, as well as to the anonymous reviewers, for many helpful questions and suggestions. I am particularly grateful to Adam Tamas Tuboly for inviting me to contribute to the conference and book, and for his many insightful comments and suggestions.

${ }^{2}$ For a detailed discussion of weaker versions of verificationism see Hans-Johann Glock's chapter in this volume.
} 
decade that followed the Second World War). ${ }^{3}$ As Ayer (1946, p. 5) himself says about the book, "for reasons not wholly dependent upon its merits, it has achieved something of the status of a text book". Like any textbook, its sketches of some of the views it presents and advocates helped to forge something which we may call the received view of Logical Empiricism in the Anglophone world. It has thus contributed to setting up one of the most important tasks faced by historians of analytic philosophy in the last three decades or so: the task of challenging this received view.

In this chapter, I will outline the ways in which $L T L$ has helped to foster various mistaken stereotypes about Logical Empiricism that would later be combined in forming the received view. I will begin by examining Ayer's all too brief presentation of an Anglocentric lineage for his ideas. This lineage, as we shall see, simply omits the major $19^{\text {th }}$ century Germanophone influences on the rise of analytic philosophy. The Germanophone ideas he presents are selectively introduced into an Anglophone context, and directed towards various concerns that arose within that context. I will focus on the differences between Carnap's version of the overcoming of metaphysics, and Ayer's reconfiguration into what he calls the elimination of metaphysics. Having discussed the above, I will very briefly outline the effect that Ayer's radicalisation of the Vienna Circle's doctrines had on the subsequent Anglophone reception of Logical Empiricism.

\section{An Anglocentric Provenance}

One of the basic difficulties that $L T L$ presents to the historian of philosophy derives from the fact that it presents its views and arguments almost as if they were completely detached from the Germanophone context in which they were initially developed. This is not, necessarily, something for which Ayer should be admonished. ${ }^{4}$ Rather, as we shall see, it may be more charitable to see this expectation as merely a by-product of the book's (perhaps partly unintentional) use as a textbook introduction to Logical Empiricism. Despite having subsequently served this goal, nowhere in the book does Ayer state that his purpose is to introduce the Vienna Circle's work to an Anglophone audience. Ayer simply sets out to present a series of abstract views and arguments, whose provenance is mostly left unexamined. Like many subsequent systematic works of analytic philosophy, the history and context of the views put forth by $L T L$ remains mostly irrelevant to its goal of arguing for or against certain philosophical positions. In some cases, the positions advocated by Ayer are simply restatements of positions defended by all or some of the Vienna Circle's members. What complicates matters further is that some of the positions advocated by Ayer turn out to be his own responses to the work of the Vienna Circle, rather than restatements thereof. In other words, LTL suffers from the absence of a clear-cut demarcation between Ayer's own views and his restatement of the Vienna Circle's. It is from this absence, as we shall see, that various confusions arise.

Ayer does not completely refrain from at least partly commenting on the provenance of his views when he vaguely acknowledges that

\footnotetext{
${ }^{3}$ Susan Stebbing was also largely responsible for introducing the Vienna Circle's ideas to British philosophers in her 1933 British Academy address; see Stebbing (1933a); see also Siobhan Chapman's discussion of Stebbing in her chapter of this volume.

${ }^{4}$ In an interview from 1989, Ayer says that he "didn't speak much German" at the time, and that "I couldn't really take much part in their debates, but I understood what was going on" (Ayer and Honderich 1991, p. 209). This may at least partly account for his ignorance of the Germanophone context in which the Vienna Circle's ideas were developed (see e.g. Carnap, Neurath and Hahn 1929/1991). Nonetheless, in that same interview, more than fifty years after $L T L$ was published, Ayer still discusses the obscurity of nonsensical German (and French) philosophy, as opposed to the clarity of English-speaking philosophy in the tradition of British Empiricism (Ayer and Honderich 1991, pp. 212-213 and 225).
} 
the philosophers with whom I am in the closest agreement are those who compose the "Viennese circle", under the leadership of Moritz Schlick, and are commonly known as logical positivists. And of these I owe more to Rudolf Carnap. (Ayer 1946, p. 32.)

In fact, Carnap's name is mentioned on nine of the 160 pages of the book $(32,44,58,59,91$, $130,140,151$ [155]), while Schlick's work is mentioned on four (32, 36, 37, 90 [159]). When it comes to other members of the Vienna Circle, the book includes two footnote mentions of Neurath (91, 151 [158]), two of Hahn (86, 136 [156]), and one of Waismann (37 [160]). As far as the Berlin circle is concerned, only Hempel gets a single footnote mention (91 [156]).

So far, this is in keeping with the book's abstract, problem-focused systematic approach. Yet the relatively marginal mentions of the influence the "Viennese circle" had on LTL can be contrasted with the first statement of the preface, which draws a particular picture of the provenance of analytic philosophy:

The views which are put forward in this treatise derive from the doctrines of Bertrand Russell and Wittgenstein, which are themselves the logical outcome of the Empiricism of Berkeley and David Hume. (Ayer 1946, p. 31)

Obviously this claim is problematic on multiple counts. It seems that, for Gilbert Ryle's envoy to Vienna, ${ }^{6}$ quickly establishing an Anglocentric provenance for his ideas takes priority over getting the facts straight about the Germanophone philosophers with whom he "is in the closest agreement" (1946, p. 32). This is corroborated by various similar attempts in LTL to establish a British lineage for analytic philosophy, arguing that Locke, Berkeley, and Hume are not metaphysicians but analysts (1946, pp. 52-55), setting up a tradition which Ayer sees as being passed on to them from Hobbes (1946, p. 55), and leading up through Bentham and Mill (1946, p. 55), to Moore and Russell, to the empiricist brand of philosophy advocated by Ayer himself. ${ }^{7}$ Ayer (1946 p. 55-56) even goes on to conclude that: "we may fairly claim that in holding that the activity of philosophising is essentially analytic we are adopting a standpoint which has always been implicit in English [sic] empiricism".

In what follows, I will come to question whether there is, indeed, anything 'fair' in this Anglicized depiction of a Germanophone philosophical tradition. I will begin by questioning the false assumptions and omissions behind the British lineage presented by Ayer, pointing towards a more accurate rendition of the history of proto-analytic philosophy.

Though this enterprise is, of course, made easier by the hindsight offered by recent work in the historiography of analytic philosophy, it is, as we shall see, a rendition that was not entirely unavailable to Ayer at the time. Thus I will take care to avoid anachronism by comparing Ayer's presentation of Logical Empiricism with other contemporary Anglophone writings on the topic. Given that Ayer's book is among the first to discuss the topic in English, there are only a relatively small number of other sources to compare him with (compared to the booming Anglophone discussions of the Vienna Circle in the decades that follow). ${ }^{8} \mathrm{~A}$ further candidate is Ernest Nagel's "Impressions and Appraisals of Analytic

\footnotetext{
${ }^{5}$ This may be compared with the acknowledgement section of his "Demonstration of the impossibility of metaphysics" from 1934, where he simply says that his views are not original, but clearer versions of those developed by Schlick, Carnap, and Wittgenstein (1934a, 335).

${ }^{6}$ According to Ayer, Ryle instructed him to spend his honeymoon in Vienna in 1933 (rather than go to Cambridge to attend Wittgenstein's lectures); see Ayer and Honderich 1991, p. 209.

7 Ayer (1936) also presented a British lineage for Logical Empiricism at the International Congress for Scientific Philosophy in Paris in 1935. (Here, he carefully distinguishes between two directions in British philosophy, the Moorean account of directive analysis which Stebbing (1933a) employs in her criticism of the Vienna Circle, and his own Russellian defence of their position.)

${ }^{8}$ By 1936, a number of Vienna and Berlin Circle members had already started publishing articles in English, e.g. Kurt Grelling (1928) Otto Neurath (1931/1983); Moritz Schlick, (1931/1979, 1932/1979, 1935/1979);
} 
Philosophy in Europe", along with LTL a seminal source for the Anglophone dissemination of Logical Empiricism. ${ }^{9}$ Both $L T L$ and Nagel's paper were published in January 1936, and so Ayer could not be expected to have read Nagel's article. Thus the comparison between Nagel and Ayer serves a very specific qualified purpose: to show that it would not be, strictly speaking, anachronistic to expect, in January 1936, of a philosopher who knew about the Vienna Circle's work to write, in English, about certain things that Ayer does not mention. ${ }^{10}$

\section{Omissions Made by Ayer's History of Logical Empiricism}

There are a number of problems with the picture of the history of analytic philosophy Ayer conjures. These have to do primarily with what is left out of the picture, as I shall proceed to show. As we will see, there may be in each case various extenuating circumstances for Ayer's omissions.

\subsection{Empiricism vs. Rationalism}

I will begin at the start of Ayer's timeline. Ayer's history begins with a stereotypical exposition of the opposition between British Empiricism and Continental Rationalism. ${ }^{11}$ This is presented as an "outstanding philosophical dispute" (1946, p. 133) in metaphysics over whether "there exists a supra-sensible world which is the object of a purely intellectual intuition and is alone wholly real" (1946, p. 134). Ayer not only appeals to this 'dispute' in order to establish the British lineage of his own position, but also to show the ways in which his brand of empiricism resolves the dispute by correcting the mistakes of his Empiricist predecessors. ${ }^{12}$ The linguistic empiricism of $L T L$ is thus presented as:

1) partly conceding the Rationalist critique of classical Empiricism, while rejecting the metaphysical conclusions the critique had driven them to;

2) in this way, fortifying empiricism by rejecting the mistaken assumptions of its classical proponents; and

3) thus both aligning itself with the Empiricist side of the dispute, and also resolving the dispute in an empiricist manner.

The abstract conception of the opposition between Empiricism and Rationalism presented by Ayer may not have been surprising to an average early twentieth-century philosophical audience. Indeed, at the time and until relatively recently, this would have been a standard version of the history of philosophy. The conception of Empiricism and Rationalism as two completely distinct and disputing 'isms' has been shown by more recent scholarship not to match the actual views of the authors who are supposedly the chief

Blumberg and Feigl (1931); Rudolf Carnap (1934a, 1934b, 1936-7); Herbert Feigl (1934); Carl G. Hempel (1934); Juhos (1935) Furthermore, a number of Anglophone discussions of logical positivism had already been available, e.g. Susan K. Langer (1930); Sidney Hook (1930); Helen Knight (1931) (which surveys, apart from new works of Neo-Scholasticism and Phenomenology, the first issue of Erkenntnis, and summarises three articles by Schlick, Carnap, Reichenbach, and Waismann); Ginsburg, E. B. (1932); Ernest Nagel (1932, 1934); Stebbing (1933a); Walter S. Gamertsfelder (1933); Victor F. Lenzen (1933); John Dewey (1934); W.V.O. Quine (1935).

${ }^{9}$ An overview of the contemporary Anglophone presentations of Logical Empiricism, including, apart from Ayer, Stebbing, and Nagel, the work of Charles Morris, is given in Pincock (forthcoming). (Of these, I will not consider Morris' book since it was published after Ayer's.) An even earlier stage in the Anglophone reception of Logical Empiricism is described in Verhaegh (forthcoming).

${ }^{10}$ Weinberg (1936) also covers a lot of the material that Ayer omitted, but was only published, after LTL.

${ }^{11}$ Of course there are continuities between early modern and Logical Empiricism; see e.g. Krisztián Pete's chapter on the connections between Ayer and Berkley's non-cognitivism.

12 In 1931 Reichenbach offers a similar presentation of his stance as a 'triumph' of both rationalism and empiricism; see Reichenbach (1931/1978). 
representatives of either camp (see e.g. Loeb (1981) and Norton (1981)). This type of questioning has led towards revisions of the traditional misunderstanding of the opposition between a British and a Continental triumvirate, which is seen by those who dispute it as disfiguring the history of early modern philosophy in order to fit a specific canon. (The canon, consisting of the work of white European males, has tended to bypass the significant contributions of non-white, non-European, non-male philosophers). It is perhaps no wonder that the three British figures that Ayer chose as his modern predecessors were also the three figures that were taught in the University programs which would end up using Ayer's book as a textbook. Whether this was intentional or not, Ayer's conception of a British early modern lineage for analytic philosophy could also be put to use in marketing $L T L$ as a textbook. In summary, Ayer's initial claim to the Britishness of his brand of empiricism relies on a series of assumptions about the history of early modern philosophy which, though canonical at the time Ayer was writing, are currently being questioned by scholarship.

Interestingly, even if we were to suspend any judgment about whether the RationalistEmpiricist dispute was ever undertaken by any philosophers, Ayer's characterization of it as a generalized metaphysical dispute is still questionable. The standard reading (i.e. that which has been undergoing the abovementioned questioning) sees the early modern clash between Empiricism and Rationalism as a disagreement primarily over epistemology, which is then extended into metaphysics (Longworth 2009, 67). Ayer's depiction of the disagreement as one between positions within metaphysics seems to serve a particular purpose: it allows Ayer to claim that Logical Empiricism, in its 'elimination' of metaphysics, can bring the unnecessary dispute to an end (via 1-3 above). But, at least at first glance, this would seem to have misunderstood what the disagreement is about.

Is there a way to show that Ayer's conception of the disagreement is not simply a misunderstanding? Perhaps Ayer's unusual characterization of the dispute as 'metaphysical' is not meant to dispute the claim that it is an epistemological dispute. Rather, Ayer may be understood to claim that the dispute is 'metaphysical' in the specific sense deployed by $L T L$. In this sense, the dispute between Empiricism and Rationalism, in its early modern formulation, is metaphysical simply because it is not resolvable by appeal to either analytic or empirically testable propositions. Though Ayer does not explicitly address it in this manner, his attempted resolution of the dispute does treat it so. Ayer should be understood to be saying that, once the metaphysical elements are eliminated, the dispute between Empiricism and Rationalism can be successfully resolved by the verificationist theory of meaning. In other words, read this way, Ayer's understanding seems to be that the dispute was reached through the employment of metaphysical pseudo-statements on both sides; the elimination of such pseudo-statements clarifies that there had been no meaningful dispute to begin with. What remains can be reformulated in terms of $L T L$ 's resolution of the pseudo-dispute.

Given the contemporary prevalence of the canonical conception of early modern philosophy in terms of an opposition between a Rationalist and an Empiricist triumvirate, Ayer's attempt to resolve the dispute is unsurprising. Neither, of course, would the acceptance of this problematic version of the history of philosophy be singularly attributable to Ayer. The more obvious gaps in Ayer's version of the history of analytic philosophy concern the long nineteenth century. This omission in Ayer's book (among other such early historical sketches) may be held at least partly responsible for analogous gaps in many subsequent historiographic attempts up until the last quarter of the twentieth century.

\subsection{The Long 19th Century}

Ayer's lineage, as outlined above, sees the British Empiricists' work being continued by Bentham and Mill (whose work Ayer (1946, p. 559 implausibly reduces to 'a development of the analyses carried out by Hume'). These names are only mentioned by Ayer in passing. The 
only non-British name that Ayer mentions as a positive nineteenth century influence on analytic philosophy is that of Ernst Mach, though both mentions of his name in LTL (pp. 122 and 137) are in conjunction with Hume's name (in reference to their development of an "atomistic psychology" (pp. 122 and 137)). As we have seen, the proto-analytic work of the early modern British Empiricists is seen by Ayer as culminating in the work of Moore, Russell, and Wittgenstein, and through them in his own work.

A canonical nineteenth century name that one may immediately recognize as absent from this history of analytic philosophy is that of Gottlob Frege. ${ }^{13}$ This may seem surprising given the significance of modern logic for the tasks Ayer wishes to undertake in his book (see e.g. 1946, pp. 80-87). Nonetheless, Frege's name is not once mentioned in Ayer's book! Clearly the modern logic Frege had developed was far from being a strong contender against the prevalence of Aristotelian logic in the teaching curricula of philosophy departments at the time Ayer was writing. ${ }^{14}$ Nonetheless, modern logic played a central role in the development of the ideas under discussion in $L T L$, and Ayer does not shy away from discussing this role. Interestingly, when Ayer talks of non-Aristotelian logic, his references are to Russell and Whitehead's Principia Mathematica rather than Frege's Begriffschrift (e.g. p. 81, and even in the 1946 preface (p. 17)).

One may attempt to excuse Ayer for this by pointing to Frege's relative obscurity at the time. With few exceptions, such as Russell's (1903, pp. 501-522) discussions of his work, Frege's name had mostly been absent from Anglophone philosophical debate during the time. ${ }^{15}$ A more notable exception is Gamertsfelder (1933, p. 108), who claims that Logical Positivism laid "its foundations on the positivistic empiricism of the 19th century, but more directly on the mathematico-physical work of Poincare, Einstein, Frege and Russell". Furthermore, Ernest Nagel's "Impressions and Appraisals of Analytic Philosophy in Europe", also published in 1936 with the aim of introducing an Anglophone audience to analytic philosophy (including the Vienna Circle), mentions Frege throughout the work. Despite siding with Russell and his theory of definite descriptions (Nagel 1936a, p. 18), Nagel otherwise presents Russell and Frege's views as closely related versions of logicism (e.g. Nagel 1936b, pp. 43-46). In comparison, though LTL contains a prolonged discussion of Russell's theory of descriptions (1946, pp. 22-25, 60-62), it fails to mention Frege's views in that discussion. Ayer even mentions the criticisms against Russell's theory put forth by Stebbing and Moore (1946, pp. 22-23), though the possibility that Frege's theory might pose a viable alternative to Russell's is not considered.

\subsection{The Neurath-Haller Thesis}

Ayer's partial historical account of the transmission of empiricism from modern British philosophers through contemporary Austrian philosophers (and back to Britain through his own work) seems to have left unanswered the question of how such British ideas found their way to Austria. How did these Germanophone authors, including Mach whom Ayer simply bundles together with Hume, come to be influenced by British Empiricism? If these are continental philosophers, should they not be working in some paradigmatically 'continental' post-Kantian tradition?

What Ayer's account has left out has been the subject of the debate surrounding what is called the Neurath-Haller thesis (Haller 1986/1991). Its first instance is sketched in the 1929 manifesto of the Vienna Circle (which Ayer could have accessed in 1936; see Carnap,

\footnotetext{
13 See also Tuboly $(2017,46-53)$ where he argues that the Vienna Circle's members themselves also underplayed Frege's influence.

${ }^{14}$ Stebbing's 1930 A Modern Introduction to Logic was an attempt to rectify this; she acknowledges Frege's significance (40, 129, 132, 181, 213, 442, 459, 486-487), but places Russell's work centre-stage.

${ }^{15}$ Frege is discussed by Linke (1926); Grelling (1928, p. 100); Black (1933).
} 
Neurath and Hahn 1929/1973). To be fair to Ayer, the manifesto only very briefly sets up the aforementioned Austrian lineage for the 'scientific conception of the world' put forth by its authors. By contrast to Ayer's Anglocentric view, the manifesto acknowledges a wide array of international influences on the Vienna Circle, among which are found the British influences noticed by Ayer. The Viennese part of the lineage includes figures such as Mach, whom Ayer does briefly mention (1946, pp. 122, 137), and Boltzmann, but also Bolzano, Brentano, and his students (including e.g. Meinong).

Rudolf Haller (e.g. 1986/1991) interpreted the mentions of these Viennese figures in the manifesto as pointing to the existence and development of a somehow particularly Austrian type of philosophy, culminating in the work of the Vienna Circle. Though there are various problems with the idea that the internationalist philosophy of the Vienna Circle is somehow an Austrian national product (see e.g Smith (1997) and Damböck (forthcoming)), the fact that various Germanophone influences are at work in the development of Logical Empiricism is simply indisputable. Haller contrasts the influence of Kant on German philosophy with the shunning of this tradition by figures at work in the Austro-Hungarian Empire such as Bolzano and later Brentano. The Brentanian development of a scientificallyminded philosophy within an empiricist tradition is seen by both Neurath and later Haller as one of the many predecessors and allies of the scientific conception of the world (see Rock (2017) and Vrahimis (2018)).

Given the vagueness of the manifesto's mentions of figures like Bolzano or Brentano, it might be unfairly anachronistic to expect an exploration of the Neurath-Haller thesis from Ayer. Even Nagel, who does explicitly address the philosophical legacies of both Bolzano (1936a, pp. 14, 18) and Brentano (1936b, p. 50), does not acknowledge any influence they may have had on Logical Empiricism. ${ }^{16}$ It should further be emphasized that the existence of an Austrian empiricist influence on the Vienna Circle would not undermine Ayer's tracing of Logical Empiricism back to its early modern British outset. It would, however, add more detail to this lineage, allowing for a framing of the Vienna Circle's work in terms of its alignment with a scientific, liberal, enlightenment oriented attitude. The required historical detail for understanding this context is not what Ayer was after, given that he was not primarily concerned with the history of ideas.

\subsection{Other Sources Ayer Does Not Mention}

There are, of course, numerous other international sources for the Vienna Circle which are, understandably, left unmentioned by Ayer. For example, Austria was clearly not the only place on the nineteenth century European continent where the development of a non-Kantian empiricist tradition can be discerned. Some other obvious examples to be mentioned here are French, such as that of Auguste Comte, from whose initial conception of 'positivism' both Ayer and the so-called 'Logical Positivists' of the Vienna Circle sought to dissociate themselves.

An interesting exception to the rule outlined above is a partial admission of influence by the French conventionalists, and specifically Poincare, who receives multiple references in $\operatorname{LTL}(82,85,95,98) .{ }^{17}$ Ayer himself is attempting to develop a type of conventionalism about

\footnotetext{
${ }^{16}$ He does note that Tarski, who is vaguely in the line of influence of Brentano, "developed a deductive theory of syntax or metalogic several years before Carnap's publications on this topic" (Nagel, 1936b, p. 50).

${ }^{17}$ The French conventionalists had a significant influence on the Vienna Circle, especially Neurath; see e.g. Haller (1979/1991) and Uebel (1997). Anglophone sources available to Ayer that mention at least the name of Poincare as an influence on Logical Empiricism include Neurath (1931/1983, p. 48) and Gamertsfelder (1933, p. 108).
} 
analytic propositions in $L T L$ (and elsewhere). ${ }^{18}$ In a later piece he would repeat the point that there was an important influence by Poincare on $L T L$, but that he "may not have stressed it so much as it deserves" (Ayer 1987, pp. 23-24, 28).

The search for a non-Kantian source of the ideas of the Vienna Circle has, during at least the past two decades, been put to the question by scholars. This is so especially in the case of Rudolf Carnap, who has been seen as at least partly responding to the Neo-Kantian philosophical tradition in which he was schooled (see e.g. Richardson (1990) and Friedman (2000)). Interpreting Carnap in light of Neo-Kantianism involves at least to some extent countenancing precisely the kind of Anglocentric perspective proposed by Ayer, according to which the Vienna Circle continues Russell's development of empiricism. It was not, however, Ayer but rather Quine who had developed the specific thesis which has been addressed in the relevant debate, namely that Carnap's Aufbau was a continuation of Russell's earlier program of (Richardson 1990).

Thus, though Ayer's presentation of Logical Empiricism's Anglocentric lineage may have partly allowed for the seeming obviousness of Quine's thesis, Ayer is not the person responsible for the particular conception of Carnap's work. In fact, by contrast to other Germanophone thinkers omitted from Ayer's account, Kant's views receive considerable treatment in LTL. Ayer does present Kant as at least partly a predecessor for the antimetaphysical stance defended in his book. ${ }^{19}$ Like Carnap $(1959$, p. 60) before him, Ayer contrasts the new anti-metaphysical approach of Logical Empiricism with earlier failed efforts to eliminate metaphysics. According to Ayer (1946, pp. 34-35), the Kantian critique of transcendent metaphysics faces serious objections, as opposed to the new empiricist "elimination of metaphysics" which $L T L$ advocates. The Kantian critique concedes too much to Rationalism when it "admit[s] that there are some truths about the world which we can know independently of existence" (1946, p. 73). Kant, along with Plato and Aristotle, are claimed by Ayer (1946, p. 56) to have primarily been concerned with working on philosophical analysis. Kant's partly analytic and anti-metaphysical concerns, however, do not prevent him from developing mistaken views (all based on the misapplication of psychological observations) such as his transcendental aesthetic (p. 84), his notion of the categorical imperative (pp. 112-113), or even his attempt "to establish the existence of a transcendent god" (p. 114) by appeal to "the phenomena of moral experience" (ibid).

\section{The Diversity within Logical Empiricism}

One of the significant features of 'Logical Empiricism', to which we are led by our above discussion, is that of the diversity of views bundled together under its aegis. The Anglocentric lineage painted by Ayer, as well as his overall presentation, seems to imply the existence of a type of uniformity, and even a systematic program at work, within Logical Empiricism. Ayer does at least partly and indirectly acknowledge that not all his sources share the same views. Of course the obvious example is the book's systematic attempt to improve on previous versions of verificationism, developing its own particular stance on the topic over the course of its two editions in 1936 and 1946.

Another example is that of $L T L$ 's brief discussion of the method of validation for synthetic a posteriori propositions (pp. 90-91). Here Ayer presents an outline of Schlick's views, and shows them to be in opposition to the views developed by Carnap, Neurath, and

\footnotetext{
${ }^{18}$ See Ayer, Whiteley and Black (1936); see also Giannoni (1971, pp. 75-76); Ben-Menahem (2006, 13-14). In the first edition of $L T L$ he argues that analytic propositions "simply record our determination to use words in a certain fashion" (LTL, p. 84), but he differentiates this in the second edition of LTL (p. 17).

${ }^{19}$ Though Kant is not directly referenced, his treatment of metaphysics may be what Carnap has in mind when he talks of metaphysics as "uncertain, on the ground that its problems transcend the limits of human knowledge" (Carnap 1932/1959, p. 60).
} 
Hempel. In doing so, $L T L$ summarily acknowledges the existence of the protocol-sentence debate. As will be explained in more detail by later chapters of this book, Ayer develops a particularly interesting hybrid view within the Circle's debates, selectively adopting elements from various sides. ${ }^{20}$ Once again, however, it must be remembered that $L T L$ is a systematic work. As a result, Ayer's hybrid view is presented as resolving the protocol-sentence debate, and thereby as being the best option for Logical Empiricism.

Here we are, once again, faced with a confusion which derives from the kind of double function which $L T L$ has served. The book is not a scholarly work on the views of the Vienna Circle, but rather presents Ayer's own views. Nonetheless it is presenting Ayer's views to an Anglophone audience with limited access, at this time, to the views the Vienna Circle had discussed in Germanophone publications. While Ayer's views are largely derived from the Circle's debates, they are also at the same time responding to and taking up original and interesting systematic positions with respect to these debates. And though Ayer's views are an example of the diversity involved within what may broadly be called Logical Empiricism, Ayer's book was at the time among the very few works written in English to discuss this movement.

The correct way to read Ayer's work would be to understand it to be one among the diversity of views and works within Logical Empiricism. It is a systematic work that enters into a conversation at its very last stages (and it is perhaps due to this that it did not receive an answer from the members of the Vienna Circle who had earlier been involved in the conversation). ${ }^{21}$ The problems underlined above are side effects of its use as an introductory textbook, which gave it a privileged place in the Anglophone reception of Logical Empiricism. Perhaps like any other book, if read by itself (as it often has been), LTL generates a number of distortions of the Vienna Circle's views, while facilitating a misunderstanding of their position within the history of philosophy. Read alongside other works, it is illuminating.

\section{The Radicalized 'Elimination' of Metaphysics?}

LTL opens with a chapter titled 'the Elimination of Metaphysics' (p. 33), where the central doctrines which are to be elaborated throughout the book are introduced, and their consequent reconfiguration of philosophy without metaphysics is discussed. Ayer presents the wellknown thesis that a metaphysical statement is "a sentence which purports to express a genuine proposition, but does, in fact, express neither a tautology nor an empirical hypothesis" (1946, p. 41) and is thereby nonsensical. This is the thesis that the rest of the book will attempt to substantiate.

Having presented this view, Ayer attempts to explain how metaphysicians fall into the error of producing such nonsense. In his attempted explanation, Ayer combines: (i) a particular interpretation of Russell's theory of descriptions, (ii) a dialogue with Carnap's "Overcoming Metaphysics through the Logical Analysis of Language", and (iii) his own prior involvement in Anglophone debates concerning the meaningfulness of metaphysics.

Ayer employs two main examples to illustrate the metaphysician's lapse into error. His first example is the linguistic employment of the term 'substance'. His second example is the metaphysical concept of Being, which extends to talk of fictional entities. What these two cases have in common is that philosophers, without having any awareness of this, are misled by the underlying grammatical structures of our everyday language into nonsensical discussions revolving around such terms.

\footnotetext{
${ }^{20}$ See the chapters of László Kocsis and Christoph Limbeck-Lilienau in this chapter.

${ }^{21}$ See also Uebel (2007, p. 334). For more detail on some of the ways in which Ayer is involved in ongoing debates within the Vienna Circle, see e.g. Thomas Uebel's, Christoph Limbeck-Lilienau's and Christian Damböck's chapters.
} 
In the case of the term 'substance', the metaphysician's confusion is due to the fact that the relevant sentences include grammatical subjects. Misled by the fact that we speak in sentences that have a subject and a predicate, Ayer claims, metaphysicians falsely conclude that there exist such things as simple entities, corresponding to grammatical subjects, to which all the "sensible appearances of a thing" (1946, p. 42) may be predicated. Ayer argues that the grammar at work here implies that the sensible appearances need to be appearances of something. Yet, according to Ayer, "logical analysis shows that what makes these 'appearances' the 'appearances of' the same thing is not their relationship to an entity other than themselves, but their relationship to one another" (1946, p. 42). In other words, the philosophical discussions concerning the existence of substances are misguided side-effects of the underlying grammar.

A similar analysis is applied by Ayer to the concept of 'Being' (which notably also has a central role to play in Carnap's critique of metaphysics). The grammatical cause for philosophical debates concerning being is traced by Ayer to the fact that "sentences which express existential propositions and sentences which express attributive propositions may be of the same grammatical form" (1946, p. 42). The similarities in grammatical form lead, according to Ayer, to the false assumption that such sentences "are of the same logical type" (p. 42). Thus attributive propositions appear to imply existence, whereas they do not. Ayer appeals to the Kantian insight that existence is not an attribute, backed by John Wisdom's (1931, 62-63) argument, according to which "if existence where itself an attribute, it would follow that all positive existential propositions were tautologies, and all negative existential propositions self-contradictory; and this is not the case" (1946, p. 43).

In other words, to use Ayer's examples,

1) Martyrs suffer

does not imply that

2) Martyrs exist.

Furthermore, 2) is not a tautology, nor would

3) Martyrs do not exist

be a contradiction.

Ayer also goes on to analyze examples of fictional entities (which Carnap does not) in an implicit dialogue with Russell's analysis of definite descriptions. In the case of statements involving fictional entities, we have a similar effect of the grammar of everyday language misleading us into thinking that these are of the same type as some sentences referring to existing things. Ayer compares the examples of

4) Dogs are faithful

and

5) Unicorns are fictitious.

Here the surface grammar misleads us into thinking that these two sentences are of the same logical type, whereas they are not. These are, again, attributive sentences, which misleadingly seem to imply the existence of the thing to which properties are being attributed. Logical 
analysis has shown us that sentences about fictional entities do not imply the existence of such entities. In other words, 5) does not imply that unicorns exist. This is the type of error that led to metaphysicians (and perhaps Ayer has Russell's portrayal of Meinong in mind here) towards assuming that fictional entities must "have a mode of real being which is different from the mode of being of existent things" (1946, p. 43).

There is a puzzle which Ayer's presentation of his analysis does not resolve concerning the relation between his theory of meaning (i.e. the contention that only tautologies and empirical hypotheses are meaningful sentences) and the type of logical analysis he is presenting here. There seems to be a gap between the verificationism he already developed, and the discussion of the misleading aspects of the surface grammar of language. It is clear that one need not be a verificationist in order to distinguish sentences into different logical types. Ayer (by contrast, for example, to Carnap (1932/1959, pp. 67-73)) does not directly address this question.

Nonetheless, his discussion of fictional entities brings back the verificationist theory of meaning in objecting to the metaphysical discussion of different modes of being. According to Ayer, the metaphysical postulation of "a special non-empirical mode of real being" (p. 43) for fictional objects is "devoid of all literal significance" (p. 43) for two reasons:

i) The first reason relies on the verificationist view according to which sentences are meaningful if they are either tautologies or empirical hypotheses. The sentence

6) Unicorns have a special non-empirical mode of real being

is neither a tautology, nor an empirical hypothesis (since there is no way of empirically "testing whether an object is real in this sense" (1946, p. 43)). Thus it is nonsense.

ii) The second reason concerns the misleading grammatical similarities between attributive and existential sentences, and the metaphysical postulation at work here is "a fallacy of the same order as the fallacy of supposing that existence is an attribute, and it can be exposed in the same way" (1946, p. 43).

Ayer is unclear on the relation between these two reasons. On the one hand, he hints towards the view that the grammatical form misleads the metaphysician into the breach of the principle of verifiability, when he claims that the mistake "comes to be made as a result of the assumption that being fictitious is an attribute" (1946, p. 43). On the other hand, as we have seen, he points out that the mistake "can be exposed in the same way" as other mistakes due to surface grammar; but such an exposition is possible independently of the verificationist theory of meaning.

\section{Ayer's Divergences from Carnap}

Though Ayer's source for the ideas he develops here is clearly Carnap, who is both cited in the relevant passages (p. 44) and mentioned in the introduction (p. 32), Ayer's account diverges from Carnap's. Carnap's (1932/1959) account involves a twofold division of the type of erroneous employment of language that leads to nonsensical metaphysics. On the one hand, there are certain metaphysical pseudo-concepts which render any sentence they are inserted into unverifiable (1932/1959, pp. 65-67). In the history of language, according to Carnap's contentious claim, these are concepts which shifted away from their original empirical content, thus deceitfully seeming still meaningful (ibid.). On the other hand, there are metaphysical pseudo-sentences, i.e. sentences that combine words in a nonsensical 
manner (1932/1959, pp. 67-68). ${ }^{22}$ Carnap here differentiates between the grammar of ordinary language, or what he calls "historico-grammatical syntax" (1932/1959, p. 69), from what he calls "logical syntax" (ibid.). The rules of the former allow for the formation of sentences which have no possible translation into logically syntactical sentences. In other words, they appear as if they are a meaningful sequence of words, given that they contain no breach of "historico-grammatical syntax". Yet the development of modern logic allows us to show that the sequence of words does not translate into a well-formed formula.

Thus, according to Carnap, modern logic is the tool that allows for the fulfillment of the attempt to overcome metaphysics undertaken by various earlier philosophical schools. Ayer's problematic encounter with Carnap's text already appears in their different choices of words. Where Carnap had talked of overcoming metaphysics ["die Überwindung der Metaphysik"] (Carnap 1932/1959, p. 60), Ayer employed the phrase "the elimination of metaphysics" (1946, p. 33). The difference in wording in fact reflects a difference in either philosopher's stance towards metaphysics.

Carnap's use of the term "overcoming" seems to refer to Nietzsche, who also talks of "die Überwindung der Metaphysik" (see e.g. Sachs 2011). Carnap also explicitly claims Nietzsche as a predecessor to the position he is defending, citing his stance towards metaphysics approvingly $(1932 / 1959$, p. 80). The choice of the term "Überwindung" reflects the purposes Carnap seems to have had in mind as the outcome of the demonstration of the linguistic errors metaphysicians fall into. In Carnap's view, the employment of meaningless metaphysical concepts and statements is a misguided, and thus futile, effort to debate in theoretical terms something which cannot be expressed in such language. In a subsequent addendum to his paper from 1957 (not available to Ayer in 1936, Carnap differentiates between cognitive meaning, and some type of emotive element of quasi-meaningfulness (1932/1959, pp. 80-81). Carnap clearly denies that metaphysical nonsense has any cognitive meaning, which is precisely what prevents such pseudo-statements from entering into a theoretical debate, where what is at stake is the assignment of truth-values to statements. Nonetheless, Carnap acknowledges that those who employ metaphysical sentences are attempting, and failing, to communicate something. ${ }^{23}$ According to Carnap (1932/1959, pp. 78-80), metaphysicians have tended to unknowingly attempt to put into theoretical terms something like their overall attitude towards life. Theory is simply the wrong medium in which to undertake this attempt. ${ }^{24}$ Carnap thus likens metaphysicians to bad poets or "musicians without musical ability" (1932/1959, p. 80), mistakenly shifting away from the proper medium in which to successfully communicate such non-theoretical attitudes towards life. Carnap's claiming of Nietzsche as a predecessor relies on his reading of Nietzsche as someone who understood this, and thus split his work between purely empirical studies on the one hand, and pure poetry on the other, thus avoiding the error of presenting his poetry as theory (ibid.). In 1929, Carnap had even presented a version of this idea to the students of the Bauhaus as an exhortation towards taking up the role metaphysics had played in culture, now that logical analysis can overcome it (Dahms 2004).

\footnotetext{
${ }^{22}$ Ayer elsewhere ("Demonstration of the impossibility of metaphysics") addresses this distinction by explaining that, like Carnap, he considers that "questions about the meaning of a concept reduce themselves to questions about the meanings of [...] the simplest proposition in which it can significantly occur" (1934a, p. 337). The absence of such an account in LTL could simply be an omission on Ayer's behalf, or it could signal Ayer's distancing himself from Carnap's account (though resolving this question would require going beyond the bounds of this inquiry).

${ }^{23}$ Ayer $(1934 a$, pp. 338,342$)$ also sees that there may be an attempt to convey emotion behind some nonsensical sequence of words.

${ }^{24}$ While later in LTL Ayer resists this conclusion, Ayer (1934a, p. 342) had briefly restated Carnap's point about metaphysics being the result of a "desire also to express their feelings about the world. Literature and the arts afford the most satisfactory medium for such expression".
} 
$L T L$, though all too quickly, indirectly stands against Carnap's position concerning the relation between metaphysics and poetry. Ayer does not refer directly to Carnap, but rather presents a version of his dialogue with C.A. Mace when he speaks of it being "fashionable to speak of the metaphysician as a kind of misplaced poet" (1946, p. 44). ${ }^{25}$ Ayer's debate with Mace, published in the pages of Analysis in 1934, had involved a rendition of Carnap's critique of Heidegger. ${ }^{26}$

Ayer puts Carnap's position, via Mace, in terms of different types of value: whereas metaphysical "statements have no literal meaning" (p. 44), they may have some value that is emotive, ethical, aesthetic or artistic. He proceeds to argue against this version of the view first of all by claiming that it misrepresents poetry, which according to Ayer usually involves sentences that are literally meaningful (though they might be false). Ayer (1946, pp. 44-45) concedes that, as Carnap also points out, there is a distinction to be made between the goals of the scientist and the artist. While the truth-value of the former's statements is central to her goals, it does not matter if the latter's work consists only of false statements. The metaphysician, Ayer points out (p. 45), unintentionally falls into the error of nonsense, while the poet tends to intentionally employ nonsense to some particular end. An unintentional lapse into nonsense does not merit, for Ayer, any attribution of aesthetic value. Ayer considers the possibility that, even after this, "there remain a number of metaphysical passages which are the work of genuine mystical feeling; and they more plausibly may be held to have moral or aesthetic value" (p. 45). He nonetheless goes on to clarify that there is no significant distinction to make between such purported insight, on the one hand, and, on the other hand, nonsense purely due to the misuse of language. As Ayer puts it, "henceforth we may pursue our philosophical researches with as little regard" (p. 45) to one as to the other.

Ayer's sentiment here does not simply reject Carnap's view of metaphysics as a misplaced attempt at expression. Ayer might also seem to be going against the spirit of a number of Logical Empiricists who had seen the project of overcoming metaphysics as involving a significant component of reclaiming from "metaphysics" what may be reformulated in empirical terms. Overcoming, rather than eliminating, metaphysics also meant extruding metaphysical elements from scientific enquiry, including the historical and social sciences. Whereas Ayer instructs us to go on with our philosophical researches, paying no heed to what we take to be metaphysical, figures like Carnap thought carefully about how to salvage the parts of our culture which have been led to metaphysical impasses.

To be fair to Ayer, he did in fact share this spirit when, in earlier work, he had clarified that "in many cases, once the work has been made to shed its metaphysical coating, pieces of genuine philosophising remain" (1934a, p. 343). He even goes against this spirit in the opposite direction when he notes that "the discovery that all metaphysical assertions are nonsensical is consistent with piety towards the great philosophers of the past" (1934a, p. 343). It may be important, however, to note that such views are offered in earlier publications by Ayer, and are omitted from $L T L$. It could thus be argued that $L T L$ not only functioned as a distortion of the Vienna Circle's views, but also offers a radicalized rendition of Ayer's earlier presentations of their views, while omitting any discussion concerning its justification. ${ }^{27}$

\section{The Aftermath}

\footnotetext{
${ }^{25}$ The dialogue begins as a response to Richards (1924) in Mace (1934a). Ayer replied in Ayer, A. J. (1934b), to which Mace responded in C. A. Mace (1934b).

${ }^{26}$ As noted above, Ayer's "Demonstration of the impossibility of metaphysics", published a month later in July 1934, also cites Carnap's article, as well as Schlick, as the sources of its arguments.

${ }^{27}$ Furthermore, Ayer had different targets and motivations than the Vienna Circle; see Vrahimis (2013a).
} 
As we have already seen, Ayer's book focused on discussions of particular problems, and only very briefly touched upon the context in which they had initially been addressed by the Vienna Circle and its predecessors. The reception of his work also followed course, and the bold claims made by $L T L$ resulted in bringing a critical debate over the viability of verificationism to the center of Anglophone philosophy during the 30s and 40s. Within this debate, there had been little concern about the acceptability of Ayer's brief history of Logical Empiricism. The differences between Ayer's and the Vienna Circle's views were overlooked, with some exceptions concerning the core doctrines of verificationism at stake during the subsequent debate. The context of the Vienna Circle's work was often deemed irrelevant to the debate, and thus its examination would be postponed until quite recently. The philosophical debate ignored the fact that the Vienna Circle was critically engaged in larger Germanophone debates. Ayer's rendition of the Vienna Circle's arguments would give Anglophone philosophy further reason why it should "pursue our philosophical researches with [...] little regard" (1946, p. 45) to the other sides involved in Germanophone debates. We can see this through the example of the difference between Carnap's engagement with Heidegger, which though vehemently polemical is still keenly aware of the opposition's standpoint (Vrahimis 2013a). It would subsequently invoke further responses within Germanophone philosophy, such as that by Horkheimer (see Horkheimer (1982); Dahms (1994, pp. 97-154); O’Neil and Uebel (2004)). By contrast, Ayer's use of Carnap's arguments, at first in a brief mention against Heidegger and later also applied against Sartre, would function as justification for Anglophone analytic philosophers not to engage with such thinkers (see Vrahimis 2013a, 2013b). Interestingly, they did not function as such for Ayer himself, who would produce a number of critical commentaries on various so-called 'continental' philosophers throughout his life. ${ }^{28}$

\section{References:}

Ayer, Alfred J. (1934a). "Demonstration of the Impossibility of Metaphysics." Mind 43 (171): 335-345.

Ayer, Alfred J. (1934b). "The Genesis of Metaphysics." Analysis 1 (4): 55-58.

Ayer, Alfred J. (1936). "The Analytic Movement in Contemporary British Philosophy." In Actes du Congrès international de philosophie scientifique, Sorbonne, Paris 1935, facs. VIII, Historie de la logique et de la philosophie scientifique. Paris: Hermann. 53-59.

Ayer, Alfred J. (1946). Language, Truth and Logic. Second edition. London: Victor Gollancz.

Ayer, Alfred J. (1987). "Reflections on Language, Truth, and Logic." In Barry Gower (ed.), Logical Positivism in Perspective: Essays on Language, Truth, and Logic. London \& Sydney: Groom Helm, 23-34.

Ayer, Alfred J. Ted Honderich (1991). “An Interview with A. J. Ayer.” In Phillips Griffiths (ed.), A. J. Ayer: Memorial Essays. Cambridge: Cambridge University Press, 209-226.

Ayer, Alfred J., C. H. Whiteley and Max Black (1936). "Truth by Convention: A Symposium." Analysis 4 (2/3): 17-32.

Ben-Menahem, Yemima (2006). Conventionalism: From Poincare to Quine. Cambridge: Cambridge University Press.

Black, Max (1933). The Nature of Mathematics: A critical survey. London: Kegan Paul, Trench, and Trubner.

Blumberg, Albert E. and Herbert Feigl (1931). "Logical Positivism: A New Movement in European Philosophy." The Journal of Philosophy 17: 281-296.

\footnotetext{
${ }^{28}$ The list of continental philosophers to whom he responded includes not only Heidegger but also, among others, Husserl, Sartre, and Merleau-Ponty; see Vrahimis (2013a, 2013b).
} 
Carnap, Rudolf (1932/1959). "The Elimination Of Metaphysics Through Logical Analysis of Language.” In Alfred J. Ayer (ed.), Logical Positivism. Glencoe, Illinois: The Free Press, 60-81.

Carnap, Rudolf (1934a). "Meaning, Assertion and Proposal." Philosophy of Science 1 (3): 359-360.

Carnap, Rudolf (1934b. The Unity of Science. Translated by Max Black. London: K. Paul, Trench, Trubner \& Co. Ltd.

Carnap, Rudolf (1936-7). "Testability and Meaning." Philosophy of Science 3 (4): 419-471 \& 4 (1): $1-40$.

Carnap, Rudolf, Hans Hahn, and Otto Neurath (1929/1973). "The scientific conception of the world: The Vienna Circle.” In Marie Neurath and Robert S. Cohen (eds.), Empiricism and Sociology. Dordrecht: D. Reidel, 299-318.

Dahms, Hans-Joachim (1994). Positivismusstreit, Die Auseinandersetzung der Frankfurter Schule mit dem logischen Positivismus, dem amerikanischen Pragmatismus und dem kritischen Rationalismus. Frankfurt: Suhrkamp.

Dahms, Hans-Joachim (2004). "Neue Sachlichkeit in the Architecture and Philosophy of the 1920s." In Stewe Awodey and Carsten Klein (eds.), Carnap Brought Home: the view from Jena. Chicago: Open Court 357-376.

Damböck, Christian (forthcoming). "(Dis-)Similarities: Remarks on 'Austrian' and 'German' Philosophy in the 19th Century." In Denis Fisette, Guillaume Fréchette and Friedrich Stadler (eds.), Proceedings of the Franz Brentano Centenary Conference, Cham: Springer, forthcoming.

Dewey, John (1934). "Meaning, Assertion and Proposal." Philosophy of Science 1 (2): 237238.

Feigl, Herbert (1934). "Logical Analysis of the Psychophysical Problem: A Contribution of the New Positivism." Philosophy of Science 1 (4): 420-445.

Friedman, Michael (2000). A Parting of Ways: Carnap, Cassirer, and Heidegger. La Salle: Chicago.

Gamertsfelder, Walter S. (1933). "Current Skepticism of Metaphysics." The Monist 43 (1): 105-111.

Giannoni, Carlo Borromeo (1971). Conventionalism in logic: A study in the linguistic foundation of logical reasoning. The Hague: Mouton.

Ginsburg, E. B. (1932). "On the Logical Positivism of the Viennese Circle." The Journal of Philosophy 29 (5): 121-129.

Grelling, Kurt (1928). "Philosophy of the Exact Sciences: its Present Status in Germany." The Monist 38 (1): 97-119.

Haller, Rudolf (1986/1991). "On the Historiography of Austrian Philosophy." In Thomas Uebel (ed.), Rediscovering the Forgotten Vienna Circle. Austrian Studies on Otto Neurath and the Vienna Circle. Dordrecht: Kluwer, 41-50.

Haller, Rudolf (1979/1991). "On Otto Neurath." In Thomas Uebel (ed.), Rediscovering the Forgotten Vienna Circle. Austrian Studies on Otto Neurath and the Vienna Circle, Dordrecht: Kluwer, 25-32.

Hempel, Carl G. (1934). "On the Logical Positivists' Theory of Truth.” Analysis 2 (4): 49-59.

Hook, Sidney (1930). "A Personal Impression of Contemporary German Philosophy." The Journal of Philosophy 27 (6): 141-160.

Horkheimer, M. (1982). "The Latest Attack on Metaphysics." In Critical theory: Selected Essays. New York: Continuum, 132-187.

Juhos, Béla (1935). "Empiricism and Physicalism." Analysis 2 (6): 81-92.

Knight, Helen (1931). "Philosophy in Germany." Journal of Philosophical Studies 5 (17): 105-112. 
Langer, Susan K. (1930). "Review: Reichenbach's Philosophie der Raum-Zeit-Lehre." The Journal of Philosophy 27 (22): 609-611.

Lenzen, Victor F. (1933). "Review: Atom and Cosmos by Hans Reichenbach." The Journal of Philosophy 30 (14): 390-391.

Linke, Paul F. (1926). "The Present Status of Logic and Epistemology in Germany." The Monist 36 (2): 222-255.

Loeb, L. (1981). From Descartes to Hume: Continental Metaphysics and the Development of Modern Philosophy. Ithaca, NY: Cornell University Press.

Longworth, Guy (2009). "Rationalism and Empiricism." In Siobhan Chapman and C. Routledge (eds.), Key Ideas in Linguistics and the Philosophy of Language. Edinburgh: Edinburgh University Press, 67-74

Mace, C. A. (1934a). "Representation and Expression." Analysis 1 (3): 33-38.

Mace, C. A. (1934b). "Metaphysics and Emotive Language." Analysis 2 (1/2): 6-10.

Nagel, Ernest (1932). "Review: Das Unendliche in der Mathematik und seine Ausschaltung by F. Kaufmann." The Journal of Philosophy 29 (15): 401-409.

Nagel, Ernest (1934). "Verifiability, truth, and verification." The Journal of Philosophy 31 (6): 141-148.

Nagel, Ernest (1936a). "Impressions and Appraisals of Analytic Philosophy in Europe, I." The Journal of Philosophy 33 (1): 5-24.

Nagel, Ernest (1936b). "Impressions and Appraisals of Analytic Philosophy in Europe, II." The Journal of Philosophy 33 (2): 29-53.

Neurath, Otto (1931/1983). "Physicalism: The Philosophy of the Viennese Circle." In Marie Neurath and Robert Cohen (eds.), Otto Neurath: Philosophical Papers, 1913-1946. Dordrecht: D. Reidel, 48-51.

Norton, D. F. (1981). “The Myth of British Empiricism.” History of European Ideas 1: 331344.

O’Neil, John and Thomas Uebel (2004). "Horkheimer and Neurath: Restarting a Disrupted Debate." European Journal of Philosophy 12 (1): 75-105.

Pincock, Christopher (forthcoming). "Logical Empiricism in the Anglophone World." In Thomas Uebel (ed.), Handbook of Logical Empiricism. New York and London: Routledge, forthcoming.

Quine, W.V.O. (1935). "Review of Logische Syntax der Sprache by Rudolf Carnap." Philosophical Review 44 (4): 394-397.

Reichenbach, Hans (1931/1978). "Aims and Methods of Modern Philosophy of Nature." In Maria Reichenbach and Robert S. Cohen (eds.), Hans Reichenbach: Selected Writings 1909-1953, Volume One. Dordrecht: D. Reidel, 359-388.

Richards, I. A. (1924). Principles of Literary Criticism. London: Routledge \& Kegan Paul.

Richardson, Alan (1990). "How Not to Russell Carnap's Aufbau." In Arthur Fine, M. Forbes and L. Wessels (ed.), PSA 1990: Proceedings of the 1990 Biennial Meeting of the Philosophy of Science Association 1: 3-14.

Rock, T. (2017). "Brentano's methodology as a path through the divide: On combining phenomenological descriptions and logical analysis." Axiomathes 27 (5): 475-489.

Russell, B. (1903). The Principles of Mathematics. Cambridge: Cambridge University Press.

Sachs, Carl B. (2011). "What is to be overcome? Nietzsche, Carnap, and Modernism as the Overcoming of Metaphysics." History of Philosophy Quarterly 28 (3): 303-318.

Schlick, Moritz (1931/1979). "The Future of Philosophy." In Henk Mulder and Barbara F. B. van de Velde-Schlick (eds.), Moritz Schlick: Philosophical Papers Volume II (19251936). Dordrecht: D. Reidel, 210-224.

Schlick, Moritz (1932/1979). "A New Philosophy of Experience." In Henk Mulder and Barbara F. B. van de Velde-Schlick (eds.), Moritz Schlick: Philosophical Papers 
Volume II (1925-1936). Dordrecht: D. Reidel, 225-237.

Schlick, Moritz (1935/1979). "Facts and Propositions." Henk Mulder and Barbara F. B. van de Velde-Schlick (eds.), Moritz Schlick: Philosophical Papers Volume II (1925-1936). Dordrecht: D. Reidel, 400-404.

Smith, Barry (1997). "The Neurath-Haller Thesis: Austria and the Rise of Scientific Philosophy." In Keith Lehrer and Johann Christian Marek (eds.), Austrian Philosophy Past and Present. Dordrecht: Kluwer, 1-20.

Stebbing, L. Susan (1930). A Modern Introduction to Logic. London: Methuen.

Stebbing, L. Susan (1933a). "Logical Positivism and Analysis." Proceedings of the British Academy 19: 53-87.

Tuboly, Adam Tamas (2017). "The Limits and Basis of Logical Tolerance: Carnap's Combination of Russell and Wittgenstein." In Peter Stone (ed.), Bertrand Russell's Life and Legacy. Wilmington: Vernon Press, 45-72.

Uebel Thomas (1997). "From the Duhem Thesis to the Neurath Principle." In Keith Lehrer and Johann Christian Marek (eds.), Austrian Philosophy Past and Present. Dordrecht: Kluwer, 87-100.

Uebel, Thomas (2007). Empiricism at the Crossroads: The Vienna Circle's ProtocolSentence Debate Revisited. Chicago: Open Court.

Verhaegh, Sander (forthcoming) "The American Reception of Logical Positivism: First Encounters (1929-1932)." HOPOS: The Journal of the International Society for the History of Philosophy of Science.

Vrahimis, Andreas (2013a). "Was There a Sun Before Men Existed?”: A. J. Ayer and French Philosophy in the fifties." Journal for the History of Analytical Philosophy 1 (9).

Vrahimis, Andreas (2013b). Encounters between Analytic and Continental Philosophy. Basingstoke: Palgrave.

Vrahimis, Andreas (2018). "The Brentano School and the History of Analytic Philosophy: Reply to Röck." Axiomathes 28 (3): 363-374.

Weinberg, Julius R. (1936). An examination of Logical Positivism. London: Kegan Paul, Trench, Trubner.

Wisdom, John (1931). Interpretation and Analysis in Relation to Bentham's Theory of Definition, London: Kegan Paul, Trench, Trubner. 